\title{
Potential Application of Gold Nanostructures in Photodynamic Therapy
}

Hemant Kumar ${ }^{1 *}$, Arvind Kumar ${ }^{2}$, Devendra Kumar Gangwar ${ }^{3}$, Prabin Kumar ${ }^{4}$, Gajendra Singh ${ }^{5}$ and Udit Soni ${ }^{6}$

${ }^{1}$ University of Hyderabad, School of Chemistry, Hyderabad -500046, India

${ }^{2}$ Department of Zoology, Bareilly College Bareilly, Bareilly, M. J. P. Rohilkhand University, Bareilly-23001, India

${ }^{3}$ Department of Chemistry, Vardhaman College, M. J. P. Rohilkhand University, Bijnor-246701, India

${ }^{4}$ Department of Chemistry, Sri Guru Tegh Bahadur Khalsa College, University of Delhi, Delhi-07, India

${ }^{5}$ Department of Chemistry, Deshbandhu College, University of Delhi, Delhi-19, India

${ }^{6}$ Department of Biotechnology, Teri University, Vasant Kunj, New Delhi-70, India

\begin{abstract}
In this manuscript we report the synthesis of gold nanostructures $\left(G_{2}\right)$ via seed-mediated growth method using CTAB as the surfactant, their size and morphology have been elucidated by TEM and DLS. The UV-visible absorption spectra of G2NPs showed a more intense peak at $680 \mathrm{~nm}$ and less intense peak at $520 \mathrm{~nm}$ indicating, formation of gold nanorods in majority. In case of $G_{2}$ nanostructures the longitudinal LSPR peak could be tunable as a function of their aspect ratio. The gold nanostructures conjugated with a photosensitizer $\left(\mathrm{G}_{2}-\mathrm{PS} \mathrm{NPs}\right)$ were applied in Photodynamic Therapy (PDT). These $\mathrm{G}_{2}-\mathrm{PS}$ NPs stably-dispersed in aqueous medium and were characterized by optical studies. Cell viability studies demonstrated that only PS conjugated NPs ( $\left.G_{2}-P S N P s\right)$ could only generate cytotoxic singlet oxygen. The results indicate the promise of $\mathrm{G}_{2}-\mathrm{PS}$ NPs as delivery agents in photodynamic therapy.
\end{abstract}

\section{Keywords: $\mathrm{G}_{2}$; TEM; EDX; XRD; PDT}

\section{Introduction}

Nanomedicine has progressed from being simple monodiagnostic or monotherapeutic platform to more complex applications such as multimodal diagnostics, externally activated therapy, and theranostic. Inorganic nanomaterials have played a major part in the latest developments owing to their stability, biological inertness, facile chemistry and certain unique properties at nanoscale.

The important aspect is the Light activated therapy which is also known as photodynamic therapy (PDT) is a noninvasively technique known for its minimal toxicity in the management and treatment of cancer and several non-malignant diseases [1-3]. It involves direct (topical) or systemic administration of a photosensitizer (PS) drug, which produces reactive singlet oxygen $\left({ }^{1} \mathrm{O}_{2}\right)$ species when irradiated with light of appropriate wavelength (visible or NIR). The cytotoxic singlet oxygen is basically responsible for PDT effects. Due to the short half-life and limited diffusion distance $(0.1 \mu \mathrm{m})$ of singlet oxygen in aqueous media, PDT effect remains localized at the irradiated (diseased) site, avoiding damage to surrounding healthy cells/tissues [4-6]. Although conceptually straightforward, effective PDT process is fraught with several drawbacks. One of the major drawbacks is that most PS drugs are hydrophobic in nature, which limits their proper biodistribution and pharmacokinetics [7-10]. This drawback can be overcome if the PS drugs are attached with nanosized carriers for better aqueous dispersion and efficient PDT action. Thus both catalysis and light activated therapy are surface phenomenon associated with size and morphology of the nanostructures.

Herein, we have synthesized of $G_{2}$ NPs, conjugated with a PS molecule, and investigated whether nano-conjugation can enhance the singlet oxygen photogeneration efficacy of the PS. The PS molecule used here is 2-diazo-3-oxo-5, 10,15,20-tetraphenylchlorin [11-15].

\section{Materials}

Cetyltrimethylammonium bromide (CTAB), Hydrogen tetrachloroaurate(III) Trihydrate $\left(\mathrm{HAuCl}_{4} \cdot 3 \mathrm{H}_{2} \mathrm{O}\right)$, Silver nitrate $\left(\mathrm{AgNO}_{3}\right)$, L-ascorbic acid, Hydrochloric acid $(\mathrm{HCl})$ solution $(1.0$
mol/L), Sodium borohydride $\left(\mathrm{NaBH}_{4}\right)$, were all purchased from Alfa Aesar, 2,9-dimethyl(1,10-phenanthroline), 3-(4,5-dimethylthiazol-2yl), 5-diphenyltetrazolium bromide (MTT) reagent, fetal bovine serum (FBS), Phosphate buffer saline (PBS), Dulbecco's modified eagle's medium (DMEM), Penicillin/Streptomycin, and Amphotericin-B and 9,10-anthracenediyl-bis(methylene) Dimalonic acid (ABMDMA) was purchased from Sigma-Aldrich.

\section{Methods}

\section{Preparation of gold nanorods $\left(G_{2}\right)$}

Synthesis of seed solution: The gold seeds were prepared as described by Nikoobakht et al. [15]. In a typical reaction, $10 \mathrm{~mL}$ aqueous solution of CTAB $(0.1 \mathrm{M})$ was mixed with $200 \mu \mathrm{L}$ of aqueous gold precursor $\mathrm{HAuCl}_{4} \cdot 3 \mathrm{H}_{2} \mathrm{O}(25 \mathrm{mM})$. Then, to this solution $600 \mu \mathrm{L}$ of ice-cold aqueous $\mathrm{NaBH}_{4}$ solution $(0.01 \mathrm{M})$ was quickly added. This leads to the controlled reduction of gold precursor into gold nanoseeds. After that, the seed solution was stirred for 2 minutes and kept at room temperature.

Seed mediated growth of $\mathrm{G}_{2}$ : The nanogold growth solution was prepared by adding of $200 \mu \mathrm{L} \mathrm{HAuCl} \cdot 3 \mathrm{H}_{2} \mathrm{O}(25 \mathrm{mM})$ to $10 \mathrm{~mL}$ DDW containing $0.1 \mathrm{M} \mathrm{CTAB}$. Then, $150 \mu \mathrm{L}$ ascorbic acid solution of $(0.1$ $\mathrm{M}$ ), along with a specific amount of $\mathrm{AgNO}_{3}$ and $\mathrm{HCl}$ were added to this solution separately. The amount of water was added to give a final mixture volume of $10 \mathrm{~mL}$. In the final mixture, the concentrations of $\mathrm{CTAB}, \mathrm{HAuCl}_{4}$ and $\mathrm{L}$-ascorbic acid were fixed at $0.1 \mathrm{M}, 0.5 \mathrm{mM}$.

*Corresponding author: Hemant Kumar, University of Hyderabad, School of Chemistry, Hyderabad -500046, India, Tel: 91403010500; E-mail: hemantuoh@gmail.com

Received December 13, 2015; Accepted Janaury 06, 2016; Published January 25, 2016

Citation: Kumar H, Kumar A, Gangwar DK, Kumar P, Singh G, et al. (2016) Potential Application of Gold Nanostructures in Photodynamic Therapy. J Nanomed Nanotechnol 7: 349. doi:10.4172/2157-7439.1000349

Copyright: $\odot 2016$ Kumar H, et al. This is an open-access article distributed under the terms of the Creative Commons Attribution License, which permits unrestricted use, distribution, and reproduction in any medium, provided the original author and source are credited. 
The $\mathrm{AgNO}_{3}$ concentration was varied from $0.06 \mathrm{mM}$ and the $\mathrm{HCl}$ concentration from $0.01 \mathrm{M}$. The colorless growth solution was kept in a room temperature, after 30 minutes and $10 \mu \mathrm{L}$ of seed solution was added to it. The resulting mixtures were left undisturbed for $20 \mathrm{~min}$ allowing seed-mediated GNPs formation to go to completion [12-14].

Formation of electrostatic conjugates of PS with $G_{2}\left(P S-G_{2}\right)$ : The PS- $G_{2}$ conjugates were formed by reaction of $P S$ and $G_{2}$ with in aqueous phase. The positive charges on the surface of $G_{2}$ NPs were electrostatically-reacted with the negative charge present in PS. Here, $50 \mu \mathrm{L}$ aqueous dispersion of PS $(1 \mathrm{mg} / \mathrm{mL})$ was added to a $1 \mathrm{~mL}$ of $\mathrm{G}_{2}$ solution $\left(10 \mathrm{mg} / \mathrm{mL}\right.$ in $\left.\mathrm{H}_{2} \mathrm{O}\right)$, and mixed with shaking at room temperature for 2 minutes [3]. After formation of the PS-nanoparticle conjugates, they were separated from the free PS via centrifugation separation and washing in the aqueous medium.

\section{Characterization}

The sizes and morphology of nanostructures were determined via transmission electron microscopy (TEM) EDX and SAED using a TECNAI G2-30 U TWIN TEM instrument (FEI, Eindhoven, The Netherlands) with an acceleration voltage of $300 \mathrm{kV}$. The size of the nanostructures was further analyzed by dynamic light scattering (DLS) measurements, using a NANO-ZS series MALVERN ZETASIZER instrument. High resolution powder X-ray diffraction (XRD) was used to analyze the phase composition of the nanostructures, using a Brukar D8 Discover $x$-ray spectrometer, over the $2 \theta$ range from $20^{\circ}-75^{\circ}$ at rate of $2.58 / \mathrm{min}$, using $\mathrm{Cu}-\mathrm{Ka}$ radiation $(\lambda=1.54060 \AA)$. The optical properties (UV-visible absorption and fluorescence emission spectra) of the gold nanostructures, drug, dye and photosensitizer samples were recorded using a Shimadzu UV-1601 spectrophotometer (Shimadzu, Kyoto, Japan) and a Cary Eclipse fluorescence spectrometer (Varian, Palo Alto, CA), respectively.

\section{Detection of singlet oxygen generation by photosensitizer via photobleaching of ABMDMA}

Photo-induced singlet oxygen generation was determined by photobleaching of the chemical probe 9, 10-anthracenediyl-bis (methylene) dimalonic acid (ABMDMA). ABMDMA is a water soluble derivative of anthracene that can be photobleached by singlet oxygen to its corresponding endoperoxide. The reaction was monitored spectrophotometrically by recording the decrease in optical den density at $400 \mathrm{~nm}$ (corresponding to the absorption $\lambda_{\text {max }}$ of ABMDMA). In a typical experiment, $0.40 \mu \mathrm{M}$ of the sodium salt of ABMDMA in water was mixed with a mixture of photosensitizer (PS) and GNPs to give a final concentration of $2 \mu \mathrm{M}$ for PS. The control experiment used 0.40 $\mu \mathrm{M}$ of the sodium salt of ABMDMA in water without any PS-GNPs mixture added. The solution was irradiated in an open quartz cuvette with continuous stirring. The absorbance measurements followed by irradiation were carried out every $10 \mathrm{~min}$. A $450 \mathrm{~W}$ xenon-mercury lamp was used as the light source [15].

\section{Results and Discussions}

$G_{2}$ NPs were prepared using seed-mediated growth methods. The $\mathrm{G}_{2}$ nanostructures have been synthesized in $20 \mathrm{~nm}$ diameter with some polydispersity, shown by TEM (Figure 1). XRD spectrum of gold nanostructures, showed diffraction peaks of 111, 200 and 220 (Figure 2 ), which match the characteristic peaks of inverse spinel oxide and the diffraction peaks delineate face-centered lattice (FCC) unit cells for the nanostructures (JCPDS 04-0785).

The UV-vis absorption spectra of aqueous dispersed $\mathrm{G}_{2}$ shown in

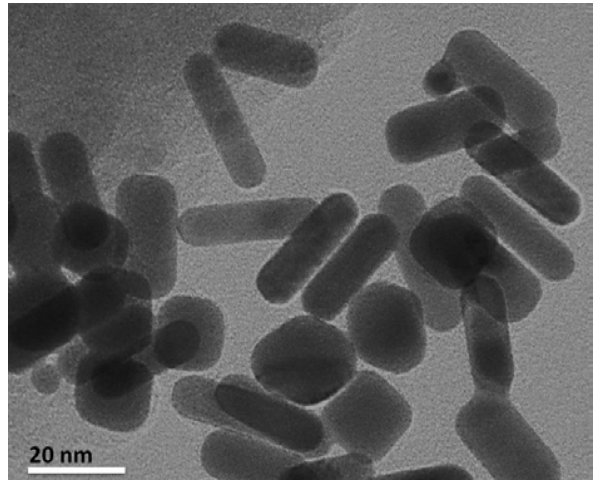

Figure 1: TEM images of $G_{2}$ showing average at scale $20 \mathrm{~nm}$ gold nanostructures.

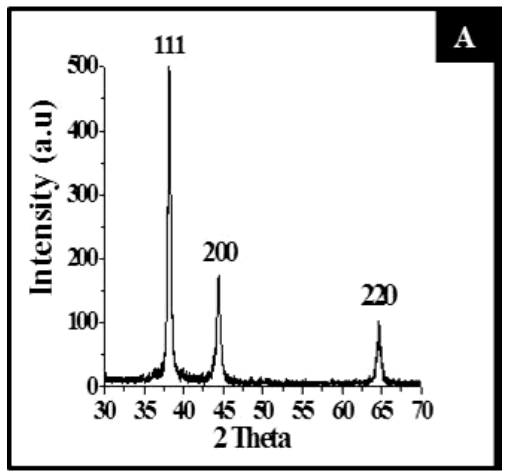

Figure 2: The powder X-ray diffraction of gold nanostructures.

Figures 3 and 4, corresponds to the LSPR phenomenon. Two peaks were observed for the $G_{2}$, the first peak (transverse peak) at $520 \mathrm{~nm}$, and the second one (longitudinal peak) at of $680 \mathrm{~nm}$, which indicates that gold nanorods were formed as major component.

\section{Use of the gold nanorods in PDT}

Gold nanostructures can also be used as a drug carrier in photodynamic therapy (PDT) of cancer [15]. PDT occurs when photoexcited molecules (called photosensitizers or PS) transfer their excess energy to molecular oxygen, leading to the formation of highly toxic and reactive oxygen species (ROS) such as singlet oxygen which can kill cancer cells when targeted at cancer sites. The UV-vis spectra of PS was taken in water, which showed characteristic absorption peaks at $438,525,567,605$ and $669 \mathrm{~nm}$.

We investigated the photogeneration of singlet oxygen by $\mathrm{G}_{2}-\mathrm{PS}$ NPs by studying the singlet oxygen mediated bleaching of the dye ABMDMA $[15,16]$. The reaction was studied by measuring the time dependent decrease in absorption of ABMDMA at $400 \mathrm{~nm}$ ( $\lambda$ max for ABMDMA) (Figure 5). When absorption spectra of PS and ABMDMA were taken individually no change in $\lambda_{\max }$ were observed, when PS has been taken with ABMDMA down to $50 \%$ decrease in $\lambda_{\max }$ was observed, but with $\mathrm{G}_{2}$-PS NPs $\lambda_{\max }$ down to $30 \%$. These absorption studies revealed that more cytotoxic singlet oxygen was generated with photosensitizer conjugated gold nanostructures and they can show promising therapeutic activity in light activated therapy (Figure 5). 


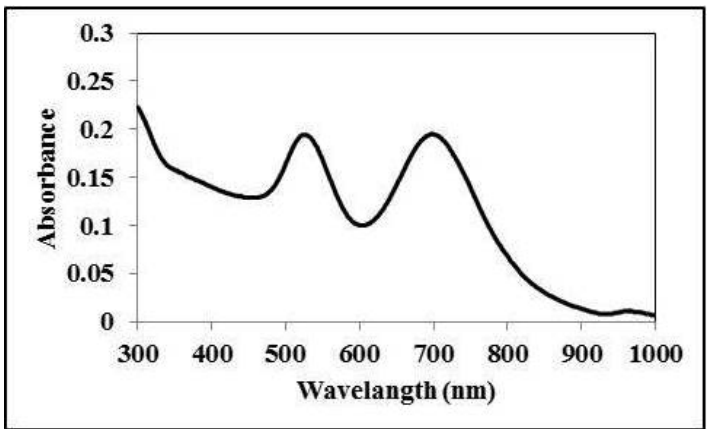

Figure 3: The Absorbance spectra of gold nanostructures.

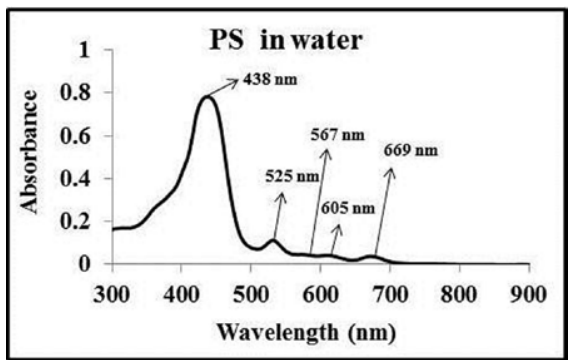

Figure 4: Absorbance spectra of PS in water solution (inset: expanded view of the long wavelength ' $Q$ ' bands of the PS).

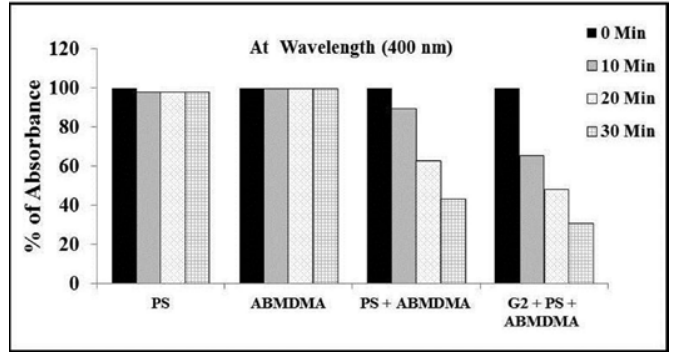

Figure 5: Combined results for all the three systems, showing decrease of $\mathrm{OD}$ at $400 \mathrm{~nm}$ (absorption maxima of ABMDMA) as a function of laser irradiation time.

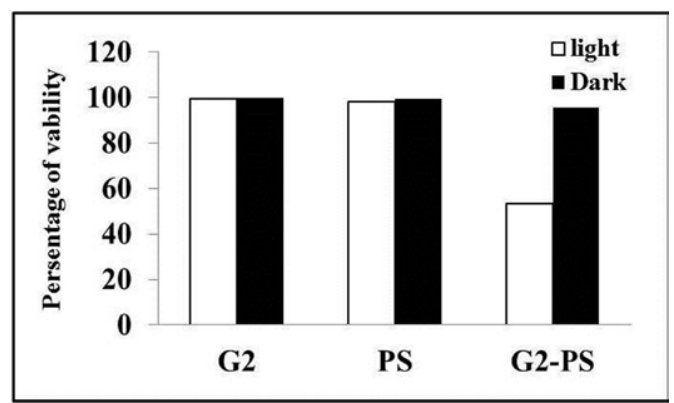

Figure 6: Percentage of cell survival of A-549 cells, after treatment with Placebo nanoparticles (G2 NPs), free PS (PS) and PS-Conjugated G2 nanoparticles (G2-PS NPs), with (light) and without (dark) subsequent irradiation with $630 \mathrm{~nm}$ laser light.

\section{In vitro toxicity}

For cell viability study human lung cancer cells A-549 grown in
DMEM media were used, supplemented with $10 \%$ fetal bovine serum (FBS), $1 \%$ antibiotic penicillin/streptomycin, and $1 \%$ antifungal amphotericin B. Approximate 1,50,000 cells/1 mL fresh media were added to each well of a sterilized 24-well plate to analyse cell viability upon treatment with various nanoparticles, and transferred back to the incubator and overnight growth, cells seeded in 24 -well plates at a confluence of about $40 \%$. The following samples were added per well in triplicates: (a) free PS $(0.15 \mu \mathrm{M}),(\mathrm{b}) \mathrm{G}_{2} \mathrm{NPs}(25 \mu \mathrm{g} / \mathrm{ml})$, and (c) $\mathrm{G}_{2}$-PS NPs $\left(0.15 \mu \mathrm{M}\right.$ PS conjugated on $25 \mu \mathrm{g} / \mathrm{ml}$ of $\left.\mathrm{G}_{2} \mathrm{NPs}\right)$. The two plates were then kept in incubator for 24 hours, then the cells were rinsed three times with sterile PBS and $500 \mu \mathrm{L}$ fresh medium per well was added. One of the plates was immediately kept in incubator (no light irradiation). The other plate was first exposed to a $635 \mathrm{~nm}$ laser light (10 mins in each well) using diode laser with output power of $20 \mathrm{~mW}$, and then returned to the incubator. After further overnight incubation, their viability was analysed by the MTT method [16-18]. The experiment was carried out in triplicates. Results shown in Figure 6 revealed that $\mathrm{G}_{2}$-PS killed upto $50 \%$ cancer cells on laser irradiation and without irradiation all cancer cells remains live, while $G_{2}$ and $P S$ both did not affect the cancer cells with or without irradiation (Figure 6).

\section{Conclusion}

In this paper, we have discussed is microemulsion mediated process for the synthesis of gold nanostructures $\left(G_{2}\right)$. Characterization methods such as TEM, XRD and absorption measurements confirmed the formation of $G_{2}$ nanostructures. The $G_{2}$ also have shown promise as drug carriers in PDT.

\section{Acknowledgement}

We are grateful to University of Hyderabad, School of Chemistry, for providing R\&D Grant to support this study. We thank Dr. Udit Soni for their help related to research work. Grant number is RC/2015/9435 (DBC-304) financial supported.

\section{References}

1. Triesscheijn M, Baas $P$, Schellens JH, Stewart FA (2006) Photodynamic therapy in oncology. Oncologist 11: 1034-1044.

2. Qiang YG, Zhang XP, Li J, Huang Z (2006) Photodynamic therapy for malignan and non-malignant diseases: clinical investigation and application. Chin Med $J$ 119: 845-857.

3. Calzavara-Pinton PG, Venturini M, Sala RA (2005) Antimicrobial photodynamic therapy: an effective alternative approach to control fungal infections. J Photochem Photobiol B 78: 1-6.

4. Dolmans DE, Fukumura D, Jain RK (2003) Photodynamic therapy for cancer Nat Rev Cancer 3: 380-387.

5. MacDonald IJ, Dougherty TJ (2001) Basic principles of photodynamic therapy J Porphyrins Phthalocyanines 5: 105-129.

6. Oleinick NL, Morris RL, Belichenko I (2002) The role of apoptosis in response to photodynamic therapy: what, where, why, and how. Photochem Photobiol Sci 1: 1-21.

7. Kästle M, Grimm S, Nagel R, Breusing N, Grune T (2011) Combination of PDT and inhibitor treatment affects melanoma cells and spares keratinocytes. Free Radic Biol Med 50: 305-312.

8. Charron G, Stuchinskaya T, Edwards R, Russell DA, Nann T (2012) Energy transfer in complexes of water-soluble quantum dots and chlorin e6 molecules in different environments. J Phys Chem C 116: 9334-9342.

9. Hirakawa K, Hirano T, Nishimura Y, Arai T, Nosaka Y (2012) Relaxation Process of Photoexcited meso-Naphthylporphyrins while Interacting with DNA and Singlet Oxygen Generation. J Phys Chem B 116: 3037-3044.

10. Cheng Y, Meyers JD, Broome AM, Kenney ME, Basilion JP, et al. (2011) Deep penetration of a PDT drug into tumors by noncovalent drug-gold nanoparticle conjugates. J Am Chem Soc 133: 2583-2591.

11. Köpke T, Pink M, Zaleski JM (2006) A facile synthesis of 2-diazo-3-oxochlorins 
Citation: Kumar H, Kumar A, Gangwar DK, Kumar P, Singh G, et al. (2016) Potential Application of Gold Nanostructures in Photodynamic Therapy. J Nanomed Nanotechnol 7: 349. doi:10.4172/2157-7439.1000349

Page 4 of 4

by lewis acid activation: selective modification of $\mathrm{p}$-electron conjugated macrocycles. Synlett 14: 2183-2186.

12. Nikoobakht B, El-Sayed MA (2003) Preparation and Growth Mechanism of Gold Nanorods (NRs) Using Seed-Mediated Growth Method. Chem Mater 15: 1957-1962.

13. Jana NR, Gearheart L, Murphy CJ (2001) Wet Chemical Synthesis of High Aspect Ratio Gold Nanorods. J Phys Chem B 105: 4065-4077.

14. Zhu J, Yong KT, Roy I, Hu R, Ding H, et al. (2010) Additive controlled synthesis of gold nanorods (GNRs) for two-photon luminescence imaging of cancer cells. Nanotechnology 21: 285106.

15. Roy I, Ohulchanskyy TY, Pudavar HE, Bergey EJ, Oseroff AR, et al. (2003)
Ceramic-based nanoparticles entrapping water-insoluble photosensitizing anticancer drugs: a novel drug-carrier system for photodynamic therapy. J Am Chem Soc 125: 7860-7865

16. Ohulchanskyy TY, Roy I, Goswami LN, Chen Y, Bergey EJ, et al. (2007) Organically modified silica nanoparticles with covalently incorporated photosensitizer for photodynamic therapy of cancer. Nano Lett 7: 2835-2842.

17. Roy I, Kumar P, Kumar R, Ohulchanskyy TY, Yong KT, et al. (2014) Ormosi nanoparticles as a sustained-release drug delivery vehicle. RSC Advances 4 $153498-53504$.

18. Kumar P, Roy Al (2014) optically and magnetically doped ormosil nanoparticles for bioimaging: Synthesis, characterization, and in vitro studies. RSC Advances. 4: $16181-16186$ 